\title{
STEREOCHEMISTRY OF THE EPOXYDON GROUP ANTIBIOTIC G7063-2 ISOLATED FROM A STREPTOMYCES SPECIES HPL Y-25711
}

\author{
G. C. S. Reddy*, R. S. Sood, S. R. Nadkarni, J. Reden, B. N. Ganguli, \\ H. W. FehlhabeR ${ }^{\dagger}$ and G. SNAtZKe ${ }^{\dagger \dagger}$ \\ Microbiology Department, Research Centre, Hoechst Pharmaceuticals Limited, \\ Mulund, Bombay 400 080, India \\ †Pharma Synthese, Hoechst AG., \\ Frankfurt, Federal Republic of Germany \\ ${ }^{+}$Bochum University, Chair of Structural Chemistry, \\ Federal Republic of Germany
}

(Received for publication August 2, 1984)

The absolute configuration of the ring system of the antibiotic G7063-2 has been established as being the same as that reported for terreic acid, based on circular dichroism data. During structure elucidation experiments, reaction with ethereal diazomethane gave an adduct whose structure is proposed.

During the course of our screening for novel broad spectrum antibiotics, a Streptomyces species HPL Y-25711, was isolated from a soil sample collected in Assam, India. From this culture a yellow crystalline antibiotic belonging to the epoxydon group was isolated and identified as 4-amino-7-oxabicyclo[4,1,0]hept - 3 - ene - 2,5 - dione - 3 - carboxamide (1). Although this antibiotic has been described earlier ${ }^{1)}$ the stereochemistry of the epoxide group has not been investigated. Now, circular dichroism data of the antibiotic and one of its derivatives are reported in comparison with those of terreic acid (2).<smiles>CC12OC1C(=O)C(C(N)=O)=C(N)C2=O</smiles>

1

\section{Results and Discussion}

Based on the physico-chemical properties (see Experimental), the antibiotic has been identified as 4-amino-7-oxa-bicyclo [4,1,0] hept-3-ene-2,5-dione-3-carboxamide (1) ${ }^{1)}$. Its absolute configuration depicted in $\mathbf{1}$ was determined from its CD-spectrum by comparison with that of (-)-terreic acid (2)*, which in turn has been chemically correlated with (-)-terremutin $(3)^{2}$. The oxidation product of terremutin was identified, however, only by mixed melting point and no chiroptical data were cited. If the two enantiomers of terreic acid formed pseudoracemates of the Roozeboom type $I^{3)}$ then this evidence would not suffice to prove

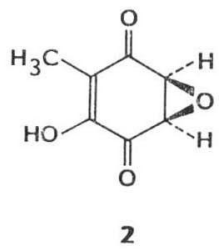

2<smiles></smiles>

3

* The wrong absolute configuration of $\mathbf{2}$ is depicted in the original literature ${ }^{2)}$. 
Fig. 1. CD spectrum of (-)-terreic acid in acetonitrile.

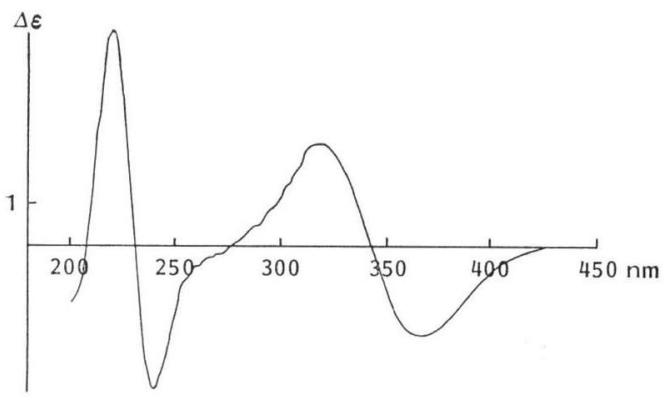

the absolute configuration of $2^{* *}$.

The CD-spectrum of (-)-terreic acid (2) is
Fig. 2. CD spectrum of $\mathbf{1}$. hydrate. In acetonitrile, ---.-- in hexafluoro acetone

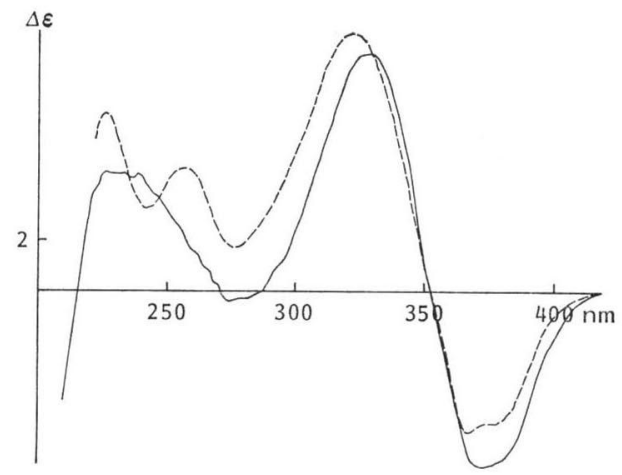
given in Fig. 1. The negative Cotton-effect around $370 \mathrm{~nm}$ corresponds to one of the two $n \rightarrow \pi^{*}$ absorptions. Another, positive Cotton effect of comparable magnitude appears around $320 \mathrm{~nm}$. The CD of $\mathbf{1}$ in the same wavelength range (Fig. 2) is very similar to that of $\mathbf{2}$ in shape, but stronger, and must correspond to the same type of excitations in both compounds, although 1 contains a cross-conjugated system. As is known for such systems ( $c f$. ref 4 ), at least the $n \rightarrow \pi^{*}$-Cotton effects are hardly influenced by this. Furthermore, the replacement of $\mathrm{OH}$ (in 2) by $\mathrm{NH}_{2}$ (in 1) will not change the chromophoric system drastically. This similarity of the CDs therefore indicates the same absolute configuration of $\mathbf{1}$ and 2. The antibiotic was reacted with ethereal diazomethane and a crystalline substance 4 was obtained. The high resolution mass spectrum of 4 indicated that its molecular formula was $\mathrm{C}_{8} \mathrm{H}_{8} \mathrm{~N}_{2} \mathrm{O}_{4}$ (MS, $\mathrm{M}^{+} m / z 196.0476$ ) and indicated that the addition of $-\mathrm{CH}_{2}-$ had occurred. Appearance of an additional narrow AB spectrum in the ${ }^{1} \mathrm{H}$ NMR around $\delta 3.1$ gave an indication that addition of $\mathrm{CH}_{2}$ must have occurred at a carbonyl<smiles>NC(=O)C1=C(N)C2(CO2)[C@H]2O[C@H]2C1=O</smiles>

4<smiles>NC(=O)C1=C(N)C(=O)[C@@H]2O[C@H]2C12CO2</smiles>

5 group. This point was further corroborated by the disappearance of a peak at $1721 \mathrm{~cm}^{-1}$ in the IR spectrum and the presence of only one carbonyl peak in the ${ }^{13} \mathrm{C} N \mathrm{NM}$ at $187 \mathrm{ppm}$. In the original compound the presence of two peaks in the ${ }^{13} \mathrm{C}$ NMR at 188.5 and 188.8 ppm was reported $^{1)}$ and attributed to the two carbonyl

groups. Hence the methylene addition product that we obtained must be 4 or 5 .

Structure 4 is favored for the following reasons. The lone pair of electrons present on the nitrogen of the amino group can lead to a resonance structure which would lower the nucleophilicity of the carbonyl group at 2. Further, a six membered chelated ring is more favorable than a five membered ring. These two factors make the carbonyl at 5 more favorable for methylene addition. The appearance of unchanged UV maxima at 244 and $292 \mathrm{~nm}$ in the methylene addition product 4 indicated that the crossconjugated chromophore remained intact. Hence structure 4 can be proposed for the diazomethane adduct.

This regio-selectivity of formation of the new oxiran ring is also proved by CD-spectroscopy. The $\mathrm{n} \rightarrow \pi^{*}$ band Cotton effect is found (Fig. 3) at nearly the same wavelength as for terremutin (3) and is of

** See footnote on page 1596. 
the same (negative) sign, although it is again one order of magnitude larger than that of 3 . The two comparable chromophoric systems must therefore have the same absolute configuration, which is only the case for $\mathbf{4}$, but not for $\mathbf{5}$.

\section{Experimental}

Melting points were determined on a Kofler micro hot stage apparatus and are uncorrected. UV spectra were taken on a Kontron Spectrophotometer (Uvikon 810). The CD was measured with a Dichrograph Mark III (ISA-JobinYvon), connected on-line to a PDP-8/e, at room temperature in cells of 0.02 to $0.1 \mathrm{~cm}$ length and a concentration of approximately $0.5 \mathrm{mg} / \mathrm{ml}$. IR spectra were run on a Perkin-Elmer spectrophotometer, model 521 using $\mathrm{KBr}$ pellets. ${ }^{1} \mathrm{H}$ NMR spectra were recorded on a Varian T-60 spectrometer and the ${ }^{13} \mathrm{C}$ spectrum recorded on a Varian CFT-20 spectrometer with tetramethylsilane as internal standard. Mass spectra were obtained on an AEIMS-902S spectrometer equipped with an on-line data system (DS-50 SH).
Fig. 3. CD spectrum in acetonitrile of 4 .

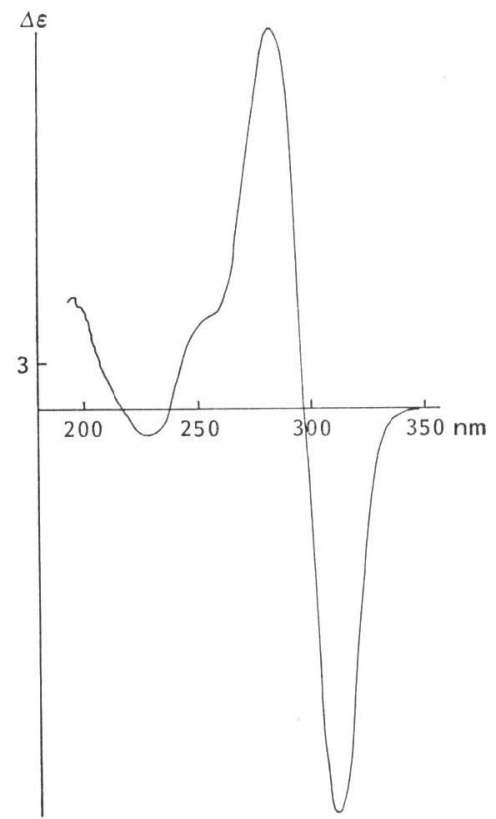

Fermentation

The organism, grown on CSPY slopes (corn starch $1 \%$, casein $0.1 \%$, peptone $0.1 \%$, yeast extract $0.1 \%, \mathrm{~K}_{2} \mathrm{HPO}_{4} 0.05 \%$ and agar $1.5 \%$ ) was transferred to a $500-\mathrm{ml}$ Erlenmeyer flask containing $60 \mathrm{ml}$ of sterile seed medium which was made of $0.5 \%$ glucose, $3 \%$ soybean meal, $5.0 \%$ dextrin, $0.7 \% \mathrm{CaCO}_{3}$ and $0.001 \% \mathrm{CaCl}_{2}$ and $\mathrm{pH}$ was adjusted to 7.5. This was grown on a rotary shaker for 48 hours at $28^{\circ} \mathrm{C}$ and was used as a seed culture. The media used for production contained $2.5 \%$ corn starch, $1.0 \%$ glucose, $0.2 \%$ yeast extract, $2.0 \%$ soybean meal, $0.5 \% \mathrm{NaCl}, 0.1 \% \mathrm{MgSO}_{4} \cdot 7 \mathrm{H}_{2} \mathrm{O}, 0.8 \% \mathrm{CaCO}_{3}$ and $1 \mathrm{ml} /$ liter trace salts solution $\left(0.007 \% \mathrm{CuSO}_{4} \cdot 5 \mathrm{H}_{2} \mathrm{O}, 0.001 \% \mathrm{FeSO}_{4} \cdot 7 \mathrm{H}_{2} \mathrm{O}, 0.008 \% \mathrm{MnCl}_{2} \cdot 4 \mathrm{H}_{2} \mathrm{O}\right.$ and $0.02 \% \mathrm{ZnSO}_{4} \cdot 7 \mathrm{H}_{2} \mathrm{O}$ ). The $\mathrm{pH}$ of the medium was adjusted to 7.5 . A $500-\mathrm{ml}$ flask containing $100 \mathrm{ml}$ of the above media was inoculated with $1 \%$ of the seed culture and incubated for 20 hours at $28^{\circ} \mathrm{C}$.

\section{Isolation and Physico-Chemical Properties of $\mathbf{1}$}

Filtered broth (8 liters) was extracted thrice with one third volume of EtOAc and the combined EtOAc extracts evaporated to dryness to obtain a dark red gummy residue weighing $2.3 \mathrm{~g}$. The crude gum was submitted to chromatography on silica gel. Elution with benzene-EtOAc (1:3) afforded a yellowish orange powder which was purified on a column of Sephadex LH-20 developed with $\mathrm{MeOH}$. The active fractions obtained crystallized from benzene-EtOAc to give a yellow crystalline product $(70 \mathrm{mg}), \mathrm{mp} 165^{\circ} \mathrm{C}(\mathrm{dec}) ; \lambda_{\mathrm{max}}^{\mathrm{MeOH}}(\varepsilon) 246(8,800), 292(13,100)$ and $356(1,800) \mathrm{nm}$; CD curve $\lambda_{\max }(\Delta \varepsilon) 376(-6.58), 327(+10.53), 233(+4.60), 198(-8.2)$ in acetonitrile; very similar after addition of trifluoroacetic acid and for hexafluoro acetone hydrate solution; $\nu_{\max }^{\mathrm{KBr}} 3436$ and 3289 $\left(-\mathrm{NH}_{2}\right), 1721,1626,1558\left(\mathrm{H}_{2} \mathrm{NCOC}(\mathrm{COR})=\mathrm{CCOR}\right)$ and $1212 \mathrm{~cm}^{-1}(-\mathrm{C}-\mathrm{O}-) ;{ }^{1} \mathrm{H}$ NMR $\left(\mathrm{DMSO}-d_{6}\right)$ $\delta 3.83(\mathrm{~d}, 4 \mathrm{~Hz}, 1 \mathrm{H}), 4.08(\mathrm{~d}, 4 \mathrm{~Hz}, 1 \mathrm{H}), 7.2$ and $10.4\left(2 \mathrm{H},-\mathrm{CONH}_{2}\right)$ and $8.4\left(\mathrm{br}, 2 \mathrm{H},-\mathrm{NH}_{2}\right)$; MS It showed a base peak molecular ion at $m / z$ 182. Fragmentation peaks at $m / z 166,137$ and 109 correspond to the loss of $\mathrm{NH}_{2}, \mathrm{CH}_{3} \mathrm{NO}$ and $\mathrm{C}_{2} \mathrm{H}_{3} \mathrm{NO}_{2}$ moieties.

Anal Calcd for $\mathrm{C}_{7} \mathrm{H}_{8} \mathrm{~N}_{2} \mathrm{O}_{4}$ : C 46.2, H 3.3, N 15.4

Found: 
Treatment of the Antibiotic with Ethereal $\mathrm{CH}_{2} \mathrm{~N}_{2}$

$50 \mathrm{mg}$ of the antibiotic were dissolved in $5 \mathrm{ml}$ of $\mathrm{MeOH}$ and excess of freshly prepared ethereal $\mathrm{CH}_{2} \mathrm{~N}_{2}$ was added. The reaction mixture was allowed to stand for 2 hours at $5^{\circ} \mathrm{C}$. Then the solvent was evaporated and the compound (4) crystallized from EtOAc/petroleum ether $\left(40 \sim 60^{\circ} \mathrm{C}\right)$ as offwhite needles $(40 \mathrm{mg}) ; \mathrm{mp} 192 \sim 194^{\circ} \mathrm{C} ; \lambda_{\max }^{\mathrm{MeOH}}(\varepsilon) 244(7,600)$ and $292(14,700) \mathrm{nm} ; \lambda_{\max }(\Delta \varepsilon) 310(-26.80)$, $283(+25.20)$, shoulder around $258(+6.0), 229(-2.0), 196(+7.4)$ in acetonitrile; $\nu_{\max }^{\mathrm{KBr}} 3448$ and 3333 $\left(-\mathrm{NH}_{2}\right), 1689(\alpha, \beta$ unsatd- $\mathrm{C}=\mathrm{O})$ and $1626($ amide $\mathrm{C}=\mathrm{O}) \mathrm{cm}^{-1} ;{ }^{1} \mathrm{H}$ NMR $\left(\mathrm{CD}_{2} \mathrm{Cl}_{2}\right) \delta 3.06$ and $3.16 \mathrm{ppm}$ (AB spectrum, $J=4.5 \mathrm{~Hz}, 2 \mathrm{H}), 3.28(\mathrm{~d}, 4 \mathrm{~Hz}, 1 \mathrm{H}), 3.61(\mathrm{~d}, 4 \mathrm{~Hz}, 1 \mathrm{H}), 6.16$ and $10.8\left(\mathrm{br},-\mathrm{CONH}_{2}\right), 8.8$ (br, $2 \mathrm{H},-\mathrm{NH}_{2}$ ); ${ }^{18} \mathrm{C}$ NMR (DMSO- $d_{8}$ ) 50.61 (d), 52.08 (t), 52.43 (d), 53.26, 94.33, 163.98, 167.96 and $187.39 \mathrm{ppm}$; MS measurements gave a $\mathrm{M}^{+}$peak at 196.0476 indicating a molecular formula $\mathrm{C}_{8} \mathrm{H}_{8} \mathrm{~N}_{2} \mathrm{O}_{4}$. Fragmentation peaks at $m / z 180,150,137$ and 94 correspond to the loss of $\mathrm{NH}_{2}, \mathrm{CH}_{4} \mathrm{ON}$, $\mathrm{C}_{2} \mathrm{H}_{3} \mathrm{O}_{2}$ and $\mathrm{C}_{3} \mathrm{H}_{4} \mathrm{O}_{3} \mathrm{~N}$ moieties.

\section{Acknowledgments}

We thank Mr. R. R. VIDWANS and Mrs. M. SARojA for their technical assistance. One of us (G. S.) thanks the Deutsche Forschungsgemeinschaft and the Fonds der Chemischen Industries for financial support and Mr. U. WAGNER for skilful CD measurements.

\section{References}

1) Noble, M.; D. Noble \& R. B. Sykes: G7063-2, a new nitrogen-containing antibiotic of the epoxydon group, isolated from the fermentation broth of a species of Streptomyces. J. Antibiotics 30:455 459, 1977

2) Miller, M. W.: The structure of terremutin. Tetrahedron 24: 4839 4851, 1968

3) Jacques, J.; A. Collet \& S. H. Wilen: Enantiomers, Racemates and Resolutions. p. 104, New York, 1981

4) Snatzke, G.; A. Konowal, A. Sablitc, N. Blazevic \& V. Sunjic: Circular dichroism of the Bochum authors. L XXVIII. Circular dichroism of optically active 1,4-benzodiazepines. Croat. Chem. Acta 55: $435 \sim 455,1982$ 